\title{
Simulation studies in the logging development program of the Canadian Forestry Service
}

\section{R. M. NEWNHAM}

Forest Management Institute Canadian Forestry Service

Ottawa, Ontario

\section{The simulation model can be used as an aid to the woodlands manager in selecting the best harvesting machine for his stand conditions, providing the limitations of the model are always remembered}

Approximately five years ago the first, very simple, simulation model of pulpwood harvesting machines was produced (Newnham 1966). The forest industry showed some interest in the results of tests made using the model, and a meeting was held in Ottawa with representatives from the industry to discuss proposals for future work in simulation. The Forestry Branch, now the Canadian Forestry Service, wanted to have some idea how best to utilize the limited resources that it had available for logging research. To provide background information for this meeting a report ${ }^{1}$ was prepared, giving proposals for future simulation research. The need to collect additional data on forest stands and on existing harvesting machines was emphasized so that more refined models could be developed. The reactions of the participants appeared to vary from scepticism, through general interest, to a belief, perhaps, that computers could solve all their problems! Now is an opportune time to review the achievements of the past five years.

The research effort of the Canadian Forestry Service was greatly expanded in 1968 with the establishment of the Logging Development Program in the Forest Management Institute. With the additional resources made available by this expansion, a number of the objectives given in the original report ${ }^{1}$ have been achieved. Information has been collected on branchiness and crown weight in pulpwood stands (Drolet et al. 1971). Data have been collected on ground roughness (microtopography), and analyses are currently being performed to determine its effect on machine mobility. Simulation studies have shown that, for a given number of trees per acre, the distribution pattern of trees has little effect on harvester productivity, but that tree size does.

On the negative side, no work has been undertaken on the classification of forest stands as to their suitability for mechanized harvesting, but this is still under active consideration. Systematic comparisons of actual with assumed operating practices have not been made although the model has

\footnotetext{
${ }^{1}$ NEWNHAM, R. M. 1966. Proposals for future work on the development of simulation models to study the effect of stand structure and spatial pattern on machine harvesting in pulpwood stands. Can. Dep. Forest., Forest Manage. Res. and Serv. Inst., Intern. Rep., FMR-3, 8 p.
}

Etudes simulées dans le programme du développement de l'exploitation du Service forestier du Canada. L'auteur trace l'historique du développement des modèles de simulation des moissonneuses d'arbres pour les bois à pâte au sein du Service forestier canadien, à partir du premier modèle simple développé en 1966, jusqu'au dernier, le "Canlog" mis de l'avant en 1971, et constamment amélioré.

On décrit brièvement l'échec obtenu pour la simulation de moissonneuses à cisailles fixes. On discute également de cette méthode utilisée lors de telles études simulées, et produisant des peuplements forestiers hypothétiques, à l'aide d'un ordinateur électronique. Le travail comprend aussi le développement d'un modèle de simulation pour les machines utilisées dans l'abattage continu. On traite finalement $d u$ développement d'un modèle simulé pour systèmes complets d'exploitation forestière, ainsi que des données d'un tel modèle pour lequel on esquisse les résultats qu'on espère obtenir.

been modified in the light of data and comments from the Pulp and Paper Research Institute of Canada (PPRIC). Rather than the staff of the Logging Development Program collecting data on operating times of harvesting machines, the information already available from PPRIC was used to check the accuracy of the simulation models.

The simulation studies of the Logging Development Program and the work undertaken in the Logging Section of the Woodlands Research Department at PPRIC are complementary. The emphasis of the simulation studies is on obtaining estimates of maximum, potential productivity of a machine while it is still on the drawing board so that improvements to the design can be made before prototype construction begins. Once a machine has been built, the PPRIC prototype studies provide far more reliable information than that obtained from simulation. However, any changes in basic design, indicated by the prototype studies, could be tested in the simulation model before being put into effect.

\section{Progress in simulation}

The original simulation model (Newnham 1966) was limited in the type of machine it could simulate and the information it produced. Because of the encouraging response of the forest industries, a new model was developed which could simulate most of the harvesting machines equipped with felling booms in existence in 1966. This was operational by the following spring and a report on it was presented at the meeting of the Woodlands Section Summer Conference on Logging held at Chicoutimi that June (Newnham 1967). The model, which used one of the LRA Feller-Buncher prototypes as a basic machine, tested the effect on machine productivity of both machine (slewing speed, boom reach, etc.) and stand (number of trees per acre, spatial pattern, etc.) parameters. Later it was used to express, in quantitative terms, the relationship between machine productivity and minimum merchantable tree size (Newnham 1968a). 
In the latter part of 1967, work was started on a simulation model for fixed-shear machines (i.e. machines with a shear mounted at the front, as the Roanoke). These machines must move from tree to tree and thus wander from the straight-line path assumed in other models. A method was derived to simulate this wandering but, after six months, it was found the logic involved in describing the machines' method of avoiding non-merchantable trees was extremely complicated and the project was abandoned. The work that was done revealed one interesting fact, namely the difficulty which these machines have in manoeuvring in the relatively dense pulpwood stands of eastern Canada. This finding has apparently been borne out in practice, for there are now few such machines operating in eastern Canada. If an attempt had been made to simulate them while they were still on the drawing board, their limitations would have been discovered earlier.

In the spring of 1968, in cooperation with the Royal College of Forestry, Stockholm, a simulation model for mechanized thinning was developed. The Swedes realized that, if thinning were to be a profitable operation, it had to be mechanized. A number of machine concepts had been proposed but, before proceeding further in their development, it was felt that a simulation model could detect weaknesses in design and indicate the most promising machine types.

The project presented a problem not encountered before in the simulation models developed in $\mathrm{Ca}$ nada where, with the exception of the model for fixed-shear machines, clear-felling was always assumed. The trees in the residual stand provided obstructions to the boom and thus restricted the points on the path of the machine from which each "marked" tree could be felled. In some instances, a marked tree could not be reached. Even if a tree could be reached and felled, the crowns of the residual trees were an obstruction to the extraction of the cut tree and either increased the extraction time or prevented extraction altogether.

The opportunity was taken to make the new model as comprehensive as possible so that it could simulate feller-bunchers, feller-processors or stump-area processors (which are quite common in Sweden). The interference between the felling and processing cycles of the machine was also taken into account. The model was thus extremely complicated and it was about a year before all the "bugs" were removed. A report was issued in 1969 (Newnham and Sjunnesson 1969) and the results of extensive series of tests were described by Newnham (1970) and by Sjunnesson (1970).

A simulation model, to study machine concepts at an early stage in the development process, is considered to be a very practical tool in Sweden. Simulation models have been used by the Logging Research Foundation (Skogsarbeten) to test machines for their supporting companies. During the past year, some Canadian manufacturers have begun to show an interest. Several machine concepts have been extensively tested for one company in particular and the conclusions reached as a result of these tests have been a major consideration in the final design of this company's harvesting machine. The model is also being used by the Australian Timber Bureau to test the Windsor Harvesting Machine (described by Silversides 1970).

As a result of these tests a number of changes and improvements have been made to the model, which has now been given the acronym CANLOG. Examples of the several types of harvesting machine which may be simulated have been given in a recent paper (Newnham 1971).

For CANLOG, data describing the forest stand and the harvesting machine to be tested are required. Stand data include the location of each tree, species code, dbh, height and volume. As many as twenty variables are required to describe the harvesting machine (see Newnham 1971, Table III).

Output from a simulation test is comprehensive (an example is given in Newnham and Sjunnesson 1969, Appendix III). Probably the most important information is a complete breakdown, such as that illustrated in Fig. 1, of the harvesting time into its components of felling and extraction, processing, moving and unloading. In the early stages of the development of a new machine this detailed breakdown indicates where improvements in design may be made. For the machine whose breakdown is illustrated in Fig. 1, the processing cycle appears to be the major factor limiting higher productivity. The processing unit of the machine is operating alone for $23.7 \%$ of the time. Thus any improvement in design which reduced the processing-cycle time could result in a maximum saving in harvesting time of $23.7 \%$ with a corresponding increase in machine productivity. The maximum savings which could be achieved by reducing the felling or moving cycles are 7.6 and $0.6 \%$ respectively. Unloading can only take place when the other machine components are idle so that any reduction in unloading time $(8.9 \%)$ would result in a reduction in harvesting time.

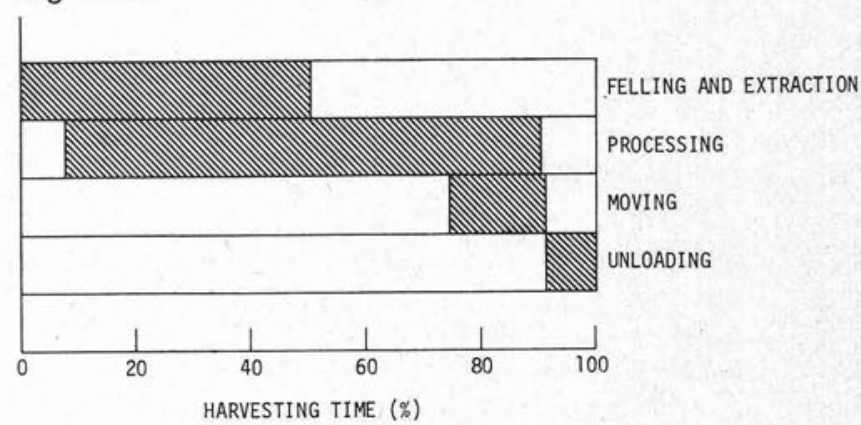

Fig. 1. An example of the breakdown of harvesting time obtained in a simulation test using CANLOG. The shaded parts of each bar indicate the proportion of the total harvesting time that the component was operating.

One important asset of CANLOG, as already stated, is that it can be used to obtain estimates of maximum, potential, machine productivity, measured in cunits of pulpwood produced per hour, while the machine is still on the drawing board. Changes in the design of the machine can then be made before prototype construction begins, 
thus reducing the time and cost of development. The effect on harvesting machine productivity of different forest stands may also be tested. Another asset of this and other simulation models is that strict control of all input variables can be maintained, only one variable at a time being varied in any series of tests.

There are disadvantages in using CANLOG to estimate machine productivity. The model can only be as reliable as the input data. No allowance for machine availability, the percentage of the scheduled operating time during which the machine is capable of doing productive work (Berard et al. 1968), is made in the model. Thus CANLOG estimates only the maximum, potential, machine productivity and should not be used for making direct comparisons between machines.

\section{Computer generation of forest stands - a by- product of the simulation studies}

The problem sometimes arises of a manufacturer asking us to test a machine concept in stands from a certain region. The only information available may be an average stand table, usually based on a large sample and therefore representative, and sometimes an estimate of average height. Some information about the spatial pattern of the tree stems in the stand may also be available.

Mapped forest stands, in which the position of each tree is known together with its dbh, total and merchantable heights, volume etc., are required for all simulation studies of harvesting machines. There are two ways of obtaining such detailed data - from the field and from the computer.

To obtain examples of stands for a region, a local operator could be asked to locate two or three typical stands, in which sample plots could then be established and the trees in them mapped and measured. When this had been done, at considerable expense, it might be discovered that the sample did not match the known stand table or average height. The process could be repeated until representative stands were found.

It is far quicker, easier and cheaper to feed the available stand data into a computer and have the computer generate representative stands. These hypothetical stands could then be checked by foresters familiar with the region and any necessary alterations made rapidly in the computer.

There are two stages in producing data that describe such hypothetical stands. The first is to generate a spatial pattern of points representing the distribution of trees in the stands (Newnham $1968 \mathrm{~b})$. The second stage is to assign size variables (dbh, total and merchantable heights, crown width, etc.) to each point in the pattern to produce the "trees". The method of producing these stands is quite complicated and has been described by Newnham and Maloley (1970).

\section{Current work}

In spite of efforts to make our simulation model as comprehensive as possible, the computer programs are constantly being updated as new ma- chine concepts are presented for testing. Fortunately, sufficient experience has now been gained that these modifications can be readily made. It is hoped that more Canadian manufacturers will seek simulation of their machine concepts early in the development process, as it is then that simulation can most help them. There are signs that this is happening more frequently, which will benefit not only manufacturers and users but also the Canadian economy as a whole.

A simulation model for "continuous-felling" machines is also being developed. The Russians have constructed one or two prototypes of such machines, and similar machines could be used in some regions of Canada where there are dense stands of small trees. These stands are often stagnant but contain a high volume of wood fibre which, at present, cannot be harvested economically by conventional systems.

In its simplest form a continuous-felling machine could consist of a bulldozer with the blade replaced by a long, single, shear blade. The trees would be felled by forcing the cutting edge through the stem at the speed of the machine. Cut trees would be windrowed to one side for extraction and processing. More sophisticated machines would be able to bundle or process the trees on the machine as well. At present no information about the forces involved in cutting trees in this way is available, as all studies of shearing forces have been made on blades cutting against an anvil or against another blade. However, these forces will be related to the length of cutting edge in contact with trees and the cross-sectional area of cut stems in contact with the blade.

Two of the important factors in designing such machines are the maximum force likely to be required in any stand and the distribution of the forces, brought about by felling, on the two tracks. For example, if the shearing blade is angled, the forces will tend to be greater on one track than the other and it may be desirable to design the machine with a different horsepower applied to each track.

The continuous-felling simulation model will calculate the cutting and friction forces (measured in inches of cutting edge and in square inches of contact surface respectively) as the machine moves through the stand. The forces transferred to each track, the maximum values of each force component, and the frequency distribution of "freerun" distances (i.e. distances between trees) will be determined. Besides a summary of this information, output from the computer will include a continuous trace of the values of each force plotted over the distance travelled. At present the model is being used to simulate the different blade configurations, illustrated in Fig. 2, in stands of different numbers of trees per acre and of different average dbh.

\section{Future work}

If sufficient interest is generated among the machinery manufacturers as a result of this project, 

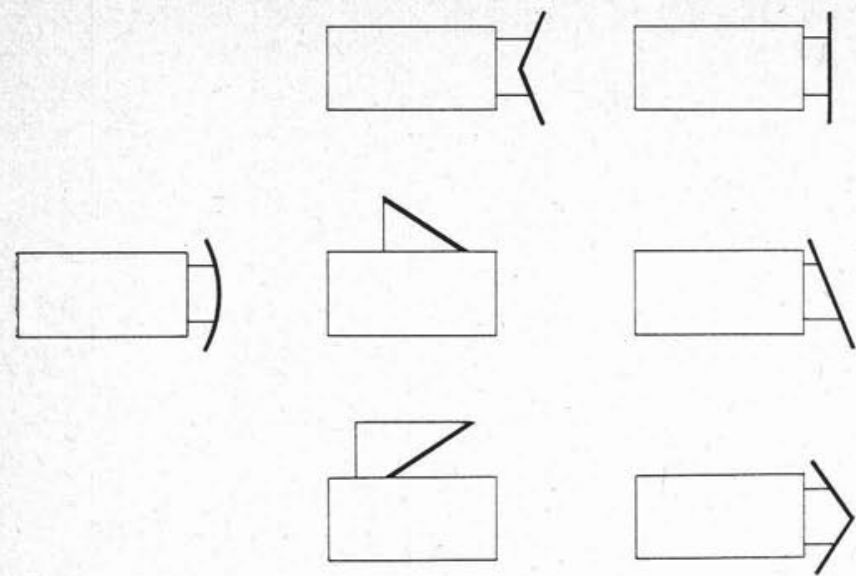

Fig. 2. Possible blade configurations in continuous-felling machines.

consideration will be given to determining the actual cutting forces involved and relating these forces to the length of cutting edge and contact surface area calculated in the model.

The harvesting-machine simulation model (CANLOG) cannot readily be used to compare the economics of harvesting machines from different logging systems. For example, is a machine which produces tree lengths at 10 cunits per hour more economical than a machine which produces shortwood at 7 cunits per hour, both piled or stored on the machine in the stump area? The solution to this problem may be obtained by studying the complete logging and transportation system, for comparisons can only be made at that point in the system where the wood from both machines has been converted to a similar product, e.g. unbarked shortwood at the roadside or chips at the mill.

The development of a simulation model for complete pulpwood harvesting systems, is under active consideration. To obtain an idea of the complexity of the model a preliminary flow-chart, showing most of the possible routes wood fibre may take from the stump to the mill, has been constructed.

The input to the system will include:

the operating cost and productivity of each machine in the system,

the frequency and duration of breakdowns for each machine,

the cost of introducing a new machine to the system,

the minimum and maximum amounts of wood that will be permitted at each storage point in the system,

the cost of storing wood at each point (interest on frozen capital), and

the route taken from the stump to the mill (or other point in the system where comparisons can be made).

If such a model is developed, valid comparisons of the different harvesting machines and logging systems could be obtained, and the effects of machine reliability on the system as a whole could be tested. A machine with high availability but with relatively low productivity, producing a steady flow of wood through the system, could be more economical than a potentially, highly-productive ma- chine with low availability which would produce disruptive surges of wood through the system.

\section{Conclusions}

The work described here has, as yet, been of little direct benefit to the woodlands manager simulation has not reduced the cost of getting wood to the mill by one cent! However, within the next two or three years very real benefits should accrue. By helping the designers and manufacturers of harvesting machines, development costs should be reduced, with subsequent savings to the user, and the time taken to introduce production models of new harvesting machines should also be reduced.

We are now confident enough to say that our simulation model, CANLOG, can be used as an aid to the woodlands manager in selecting the best harvesting machine for his stand conditions, providing the limitations of the model are always remembered. The harvesting system simulator, once developed, should be of even greater assistance in this respect.

Maximum benefits to the industry can only be obtained by keeping the practical man informed of the latest research findings and by maintaining a constant dialogue between practitioner and researcher. In this way research workers can try and find solutions to industry's problems.

\section{References}

BERARD, J. A., D. H. W. DIBBLEE and C. D. HORNCASTLE. 1968. Standard definitions for machine availability and utilization. Pulp Pap. Mag. Can. 69(1): 94-96.

DROLET, J.-C., R. M. NEWNHAM and T. B. TSAY. 1971 Branchiness of jack pine, black spruce and balsam fir in relation to mechanized delimbing. Can. Dep. Environ., Forest Manage. Inst., Inform. Rep. FMR-X-34. 34 p.

NEWNHAM, R. M. 1966. A simulation model for studying the effect of stand structure on harvesting pattern. Forest. Chron. 42: 39-44.

1967. A progress report on the simulation mode for pulpwood harvesting machines. Can. Dep. Forest. and Rural Develop., Forest Manage. Res. and Serv. Inst., Inform.. Rep. FMR-X-6, 41 p.

1968a. Minimum merchantable tree size and machine productivity - a simulation study. Pulp Pap. Mag. Can. 69 (C): 227-229.

1968b. The generation of artificial populations of points (spatial patterns) on a plane. Can. Dep. Forest. and Rural Develop., Forest Manage. Inst., Inform. Rep. FMR-X-10, 28 p.

1970. Productivity of harvesting machines designed for thinning: estimation by simulation. Can. Dep. Fish. and Forest., Forest Manage. Inst., Inform. Rep. FMR-X25,29 p.

1971. CANLOG - the new CFS harvesting machine simulator. Pulp Pap. Mag. Can. 72(3): 107-112.

NEWNHAM, R. M. and G. T. MALOLEY. 1970. The generation of hypothetical forest stands for use in simulation. Can. Dep. Fish. and Forest., Forest Manage. Inst., Inform. Rep. FMR-X-26, $41 \mathrm{p}$.

NEWNHAM, R. M. and S. SJUNNESSON. 1969. A FORTRAN program to simulate harvesting machines for mechanized thinning. Can. Dep. Fish. and Forest., Forest Manage. Inst., Inform. Rep. FMR-X-23. 48 p.

SILVERSIDES, C. R. 1970. The Windsor tree harvester. Can. Pulp Pap. Assoc., Woodlands Sec. Index No. 2586, 4 p.

SJUNNESSON, S. 1970. Ett exempel på simulering som analysinstrument för man-maskinsystem vid gallring. (An example of simulation as a tool for analysis of manmachine systems for thinning). Skogshögskolan, Inst. för Skogsteknik, Rapporter och Uppsatser 42, 60 p. 